\title{
KAJIAN RISIKO LONGSOR BUKIT TUI KELURAHAN KOTO PANJANG KECAMATAN PADANG PANJANG TIMUR
}

\author{
Bobby De Vakumela Putra ${ }^{1}$, Triyatno ${ }^{2}$ \\ Program Studi Geografi \\ Fakultas Ilmu Sosial, Universitas Negeri Padang \\ Email : Bobbydevakumelaputra@gmail.com
}

\begin{abstract}
ABSTRAK
Penelitian ini bertujuan untuk (1) mengetahui bahaya bencana tanah longsor di Bukit Tui Kelurahan Koto Panjang Kecamatan Padang Panjang Timur, (2) mengetahui kerentanan bencana longsor (3) mengetahui kapasitas bencana tanah longsor. (4) mengetahui risiko bencana tanah longsor.

Metode yang digunakan adalah metode survei dan menggunakan teknik analisis overlay yang digunakan untuk menganalisis tingkat bahaya, kerentanan,serta risiko bencana alam longsor. Hasil penelitian ini berupa (1) tingkat bahaya longsor yaitu tingkat sedang dengan luas 17,64 $\mathrm{Ha}$ persentase $86,55 \%$, tingkat bahaya rendah dengan luas $2,76 \mathrm{Ha}$ persentase $13,4 \%$. (2) tingkat kerentanan bencana sedang. (3) Tingkat kapasitas bencana longsor yaitu rendah (4) Tingkat risiko bencana yaitu sedang dengan luas 17,93 ha persentase $87,93 \%$ dan rendah dengan luas 2,46 Ha persentase $12,06 \%$.
\end{abstract}

Kata Kunci: Bahaya, kerentanan, kapasitas, risiko

\begin{abstract}
This research of aims are (1) determine the hazard of landslide disaster in Bukit Tui Koto Panjang Village, East Padang Panjang Subdistrict, (2) To know the vulnerability of landslide disaster (3) to know the capacity of landslide disaster. (4) Know the risk of landslide disaster.

The method used is a survey method and uses overlay analysis techniques that are used to analyze the level of hazard, vulnerability, and the risk of landslide natural disasters. The result of this research are (1) the level of landslide hazard that is medium level with wide 17,64 Ha percentage $86,55 \%$, low danger level with wide of 2,76 Ha percentage 13,4\%. (2) Medium disaster vulnerability level (3) The capacity level of landslide disaster is low (4) Disaster risk level is medium with 17,93 ha percentage $87,93 \%$ and low with wide 2,46 Ha percentage 12,06\%.
\end{abstract}

Key word : Hazzard, Vulnerability, Capacity, Risk 


\section{PENDAHULUAN}

Industri pertambangan merupakan salah satu industri unggulan pemerintah Indonesia untuk mendatangkan devisa negara. Industri ini juga menyedot tenaga kerja dan juga sumber pendapatan bagi pemerintah daerah yang mengelola industri pertambangan tersebut. Selain membawa banyak keuntungan, industri pertambangan ini jugamembawa kerugian bagi lingkungan dan masyarakat sekitar tambang. Kerugian tersebut salah satunya yaitu bencana longsor.

Menurut Sunarto dalam Triton PB (2009 : 165) bencana tanah longsor adalah gerakan massa tanah dan atau batuan menuruni lereng akibat gaya beratnya sendiri dan gerak massa tanah dan atau batuan itu ada yang memicu maupun ada yang memacu. Pemicu tanah longsor antara lain: Intensitas Hujan, ketebalan lapisan lempung, gempa bumi, kelerengan.

Menurut Nandi (2007 : 6) tanah longsor secara umum adalah perpindahan material pembentuk lereng berupa batuan, bahan rombakan, atau tanah atau material laporan, bergerak ke bawah atau keluar lereng. Secara geologi tanah longsor adalah suatu peristiwa geologi dimana terjadi pergerakan tanah seperti jatuhnya bebatuan atau gumpalan besar tanah.

Menurut Nandi (2007:6) gejala umum tanah longsor ditandai dengan munculnya retakan-retakan di lereng yang sejajar dengan arah tebing, biasanya terjadi setelah hujan, munculnya mata air baru secara tiba- tiba dan tebing rapuh serta kerikil mulai berjatuhan

Kota Padang Panjang memiliki sejarah longsor di kawasan tambang kapur yang terletak di Bukit Tui Kelurahan Tanah Hitam Kecamatan Padang Panjang Timur. Kejadian ini terjadi pada tanggal 4 Mei 1987 yang menimbulkan korban jiwa sebanyak 131 jiwa, Sembilan orang hilang, 29 bangunan hancur dan 15 bangunan rusak (Antara news, 2010).

Saat sekarang ini kegiatan penambangan batu kapur di kawasan Bukit Tui terus berlangsung. Kegiatan penambangan ini berlokasi sekitar $1 \mathrm{~km}$ arah timur lokasi bencana longsor tahun 1987 tepatnya di Desa Rao-Rao Kecamatan Padang Panjang Timur. Tambang ini berupa tambang terbuka yang ditambang secara tradisional oleh penambang yang berdomisili di sekitar kawasan Bukit Tui.

Berdasarkan pengamatan di lokasi, penambangan ini berada di pinggang Bukit Tui dengan kemiringan lereng yang cukup curam dan di bagian lembah kawasan pertambangan ini terdapat permukiman yang berjarak 30 m sampai dengan 100 m dari kawasan penambangan batu kapur ini.

Berdasarkan pengamatan sementara di lokasi aktivitas penambangan ini akan dapat menimbulkan risiko bencana longsor kembali. Permasalahan ini dikarenakan beberapa hal yaitu kemiringan lereng yang cukup curam, jarak permukiman yang relatif dekat dengan lokasi penambangan. Ditambah lagi dengan curah hujan rata -rata di Kota Padang Panjang dari tahun 2011 hingaa tahun 2016 mencapai 4027,8 
$\mathrm{mm}$ tentu akan menambah risiko bencana longsor di kawasan tersebut (Padang Panjang dalam Angka, 2017).

Risiko bencana (Risk) adalah potensi kerugian yang ditimbulkan akibat bencana pada suatu wilayah dan kurun waktu tertentu yang dapat berupa kematian, luka, sakit, jiwa terancam, hilangnya rasa aman, mengungsi, kerusakan atau kehilangan harta, dan gangguan kegiatan masyarakat akibat kombinasi dari bahaya, kerentanan, dan kapasitas dari daerah yang bersangkutan (Perka BNPB No 2 Tahun 2012).

Jika bencana longsor ini terjadi di lokasi tersebut secara langsung akan mengancam keselamatan penambang dan masyarakat yang tinggal dekat dengan lokasi penambangan ini. Hal ini akan menimbulkan korban jiwa dan juga kerugian materi. Untuk mengantisipasi hal tersebut maka diperlukan mitigasi bencana longsor yang berguna agar meminimalisir korban jiwa dan juga kerugian materi bagi masyarakat sekitar.

Berdasarkan penjelasan di atas maka penulis tertarik untuk mengangkat tema penelitian dengan judul : Kajian Risiko Longsor Bukit Tui Kecamatan Padang Panjang Timur

\section{Tujuan Penelitian}

Berdasarkan latar belakng dan permasalahan yang ada, maka tujuan dari penelitian ini adalah

1. Mengetahui bagaimana bahaya bencana tanah longsor di Bukit Tui Kelurahan Koto Panjang Kecamatan Padang Panjang Timur.

2. Mengetahui kerentanan bencana longsor Bukit Tui Kelurahan Koto
Panjang Kecamatan Padang Panjang Timur.

3. Mengetahui kapasitas bencana tanah longsor di Bukit Tui Kelurahan Koto Panjang Kecamatan Padang Panjang Timur.

4. Mengetahui risiko bencana tanah longsor di Bukit Tui Kelurahan Koto Panjang Kecamatan Padang Panjang Timur

\section{METODE PENELITIAN}

Untuk mencapai tujuan dari penelitian ini, digunakan dua jenis metode penelitian yaitu kuantitatif dan kualitatif (Mix Method). Penelitian kuantitatif di gunakan untuk meneliti Risiko bencana logsor, ancaman bencana longsor dan kerentanan bencana longsor. Penelitian kualitatif digunakan untuk meneliti kapastias bencana longsor.

Data yang digunakan dalam penelitian ini yaitu data primer dan data sekunder. Data primer berupa hasil wawancara kapasitas. Data sekunder berupa peta administrasi, peta lereng, peta arah lereng, peta geologi, peta jenis tanah, peta penggunaan lahan kawasan Bukit Tui Kelurahan Koto Panjang, dan data penduduk yang terdapat di kawasan Bukit Tui Kelurahan Koto Panjang.

Teknik analisis data yang digunakan dalam pembuatan tujuan penelitian yaitu:

1. Bahaya Bencana Longsor

Untuk metode yang digunakan dalam pembuatan peta bahaya bencana longsor digunakan metode deterministik yang mengacu pada tabel 1. 
Tabel 1 Metode Deterministik Ancaman Bencana Longsor

\begin{tabular}{|c|c|c|c|c|c|c|}
\hline $\begin{array}{l}\mathrm{N} \\
\mathrm{O}\end{array}$ & Data & Parameter & Pengkelasan & $\begin{array}{l}\text { Nilai } \\
\text { Kelas }\end{array}$ & Skor & Bobot \\
\hline \multirow[t]{16}{*}{1} & \multirow{16}{*}{ DEM } & \multirow{4}{*}{$\begin{array}{l}\text { Kemirin } \\
\text { gan } \\
\text { lereng }\end{array}$} & $15-30 \%$ & 1 & 0,250 & \multirow[t]{4}{*}{0,3} \\
\hline & & & $30-50 \%$ & 2 & 0,500 & \\
\hline & & & $50-70 \%$ & 3 & 0,750 & \\
\hline & & & $>70 \%$ & 4 & 1,00 & \\
\hline & & \multirow{8}{*}{$\begin{array}{l}\text { Arah } \\
\text { Lereng } \\
\text { (aspect) }\end{array}$} & Utara & 1 & 0,125 & \multirow[t]{8}{*}{0,05} \\
\hline & & & Barat Laut & 2 & 0,250 & \\
\hline & & & Barat & 3 & 0,375 & \\
\hline & & & $\begin{array}{l}\text { Timur } \\
\text { Laut }\end{array}$ & 4 & 0,500 & \\
\hline & & & Barat Daya & 5 & 0,625 & \\
\hline & & & Timur & 6 & 0,750 & \\
\hline & & & Tenggara & 7 & 0,875 & \\
\hline & & & Selatan & 8 & 1,000 & \\
\hline & & \multirow{4}{*}{$\begin{array}{l}\text { Panjang/ } \\
\text { Bentuk } \\
\text { Lereng }\end{array}$} & $<200 \mathrm{~m}$ & 1 & 0,250 & \multirow[t]{4}{*}{0,05} \\
\hline & & & $\begin{array}{l}200-500 \\
m\end{array}$ & 2 & 0,500 & \\
\hline & & & $\begin{array}{l}500-1000 \\
\mathrm{~m}\end{array}$ & 3 & 0,750 & \\
\hline & & & $>1000 \mathrm{~m}$ & 4 & 1,000 & \\
\hline \multirow[t]{8}{*}{2} & \multirow[t]{8}{*}{$\begin{array}{l}\text { Geol- } \\
\text { ogi }\end{array}$} & \multirow[t]{3}{*}{\begin{tabular}{|l} 
Tipe \\
Batuan
\end{tabular}} & $\begin{array}{l}\text { Batuan } \\
\text { Aluvial }\end{array}$ & 1 & 0,333 & \multirow[t]{3}{*}{0,2} \\
\hline & & & $\begin{array}{l}\text { Batuan } \\
\text { Sedimen }\end{array}$ & 2 & 0,667 & \\
\hline & & & $\begin{array}{l}\text { Batuan } \\
\text { Vulkanik }\end{array}$ & 3 & 1,000 & \\
\hline & & \multirow{5}{*}{$\begin{array}{l}\text { Jarak dari } \\
\text { Patahan / } \\
\text { Sesar aktif }\end{array}$} & $>400 \mathrm{~m}$ & 1 & 0,200 & \multirow[t]{5}{*}{0,05} \\
\hline & & & $\begin{array}{l}300-400 \\
m\end{array}$ & 2 & 0,400 & \\
\hline & & & $\begin{array}{l}200-300 \\
\mathrm{~m}\end{array}$ & 3 & 0,600 & \\
\hline & & & $\begin{array}{l}100-200 \\
m\end{array}$ & 4 & 0,800 & \\
\hline & & & $0-100 \mathrm{~m}$ & 5 & 1,000 & \\
\hline \multirow[t]{7}{*}{3} & \multirow[t]{7}{*}{ Tanah } & \multirow{3}{*}{\begin{tabular}{|l} 
Tipe \\
Tanah \\
(tekstur \\
tanah)
\end{tabular}} & Berpasir & 1 & 0,333 & \multirow[t]{3}{*}{0,1} \\
\hline & & & $\begin{array}{l}\text { Berliat - } \\
\text { Berpasir }\end{array}$ & 2 & 0,667 & \\
\hline & & & Berliat & 3 & 1,000 & \\
\hline & & \multirow{4}{*}{$\begin{array}{l}\text { Kedalam- } \\
\text { an Tanah } \\
\text { (Solum) }\end{array}$} & $<30 \mathrm{~cm}$ & 1 & 0,250 & \multirow[t]{4}{*}{0,05} \\
\hline & & & $30-60 \mathrm{~cm}$ & 2 & 0,500 & \\
\hline & & & $60-90 \mathrm{~cm}$ & 3 & 0,750 & \\
\hline & & & $>90 \mathrm{~cm}$ & 4 & 1,000 & \\
\hline \multirow[t]{3}{*}{4} & \multirow{3}{*}{$\begin{array}{l}\text { Hidro- } \\
\text { logi }\end{array}$} & \multirow{3}{*}{$\begin{array}{l}\text { (Curah } \\
\text { Hujan } \\
\text { Tahunan) }\end{array}$} & $<2000 \mathrm{~mm}$ & 1 & 0,333 & \multirow[t]{3}{*}{0,2} \\
\hline & & & $\begin{array}{l}2000- \\
3000 \mathrm{~mm}\end{array}$ & 2 & 0,667 & \\
\hline & & & $>3000 \mathrm{~mm}$ & 3 & 1,000 & \\
\hline & & & Ind & 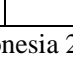 & 6 & \\
\hline
\end{tabular}

diklasifikasi menjadi tiga kelas yaitu rendah, sedang, tinggi. Informasi klasifikasi skoring dapat dilihat pada tabel 2.
Tabel 2 Klasifikasi Tingkat Bahaya Longsor

\begin{tabular}{|c|c|r|c|}
\hline No & $\begin{array}{c}\text { Tingkat } \\
\text { Risiko }\end{array}$ & $\begin{array}{c}\text { Nilai } \\
\text { Kelas }\end{array}$ & Interval Skor \\
\hline 1 & Rendah & 1 & 0,333 \\
\hline 2 & Sedang & 2 & $0,333-0,666$ \\
\hline 3 & Tinggi & 3 & $>0,666$ \\
\hline
\end{tabular}

Sumber : Pengolahan Data

2. Kerentanan Bencana Longsor

Metode kerentanan bencana terdiri dari empat parameter yaitu kerentanan sosial, kerentanan fisik, kerentanan ekonomi, kerentanan lingkungan. Dari empat parameter tersebut dilakukan kalkulasi dengan formula:

Kerentanan $=(0,4 \quad \mathrm{x}$ skor kerentanan sosial $)+(0,25 \times$ skor kerentanan ekonomi $)+(0,25 \mathrm{x}$ skor kerentanan fisik $)+(0,1 \quad \mathrm{x}$ kerentanan lingkungan)

Sumber : Perka BNPB No 2 Tahun 2012

a. Kerentanan Sosial

Dalam menentukan kerentanan sosial ditentukan oleh beberapa indikator yaitu parameter kepadatan penduduk, parameter jenis kelamin, parameter jumlah penduduk miskin, parameter orang cacat, dan parameter kelompok umur. Informasi klasifikasi kerentanan sosial mengacu pada tabel 3. Formula untuk mendapatkan kerentanan sosial yaitu

Kerentanan Sosial $=$ 
$\left(0.6 x\left(\frac{\log \left(\frac{\text { kepadatanpenduduk }}{0.01}\right)}{\log \left(\frac{100}{0.01}\right)}\right)+\right.$

(0.1 $x$ rasio jenis kelamin $)+$

(0.1 $x$ rasio kemiskinan) +

(0.1 $x$ rasio orang cacat $)+$

(0.1 $x$ rasio kelompok umur) )

Tabel 3 Parameter Kerentanan Sosial

\begin{tabular}{|l|l|l|l|l|}
\hline No & Parameter & Rendah & Sedang & Tinggi \\
\hline 1 & $\begin{array}{l}\text { Kepadatan } \\
\text { Penduduk }\end{array}$ & $<500$ & $500-1000$ & $>1000$ \\
\hline 2 & $\begin{array}{l}\text { Rasio Jenis } \\
\text { Kelamin }\end{array}$ & $<20 \%$ & $20-40 \%$ & $>40 \%$ \\
\hline 3 & $\begin{array}{l}\text { Rasio } \\
\text { Penduduk } \\
\text { miskin }\end{array}$ & $<20 \%$ & $20-40 \%$ & $>40 \%$ \\
\hline 4 & $\begin{array}{l}\text { Rasio Orang } \\
\text { Cacat }\end{array}$ & $<20 \%$ & $20-40 \%$ & $>40 \%$ \\
\hline 5 & $\begin{array}{l}\text { Rasio } \\
\text { Kelompok } \\
\text { Umur }\end{array}$ & $<20 \%$ & $20-40 \%$ & $>40 \%$ \\
\hline
\end{tabular}

Sumber: Perka BNPB no 2 Tahun 2012

b. Kerentanan Ekonomi

Dalam menentukan tingkat kerentanaan ekonomi ditentukan oleh dua parameter yaitu parameter lahan produktif, dan Produk domestik bruto daerah (PDRB). Parameter lahan produktif terdiri dari lahan produktif pertanian dan pertambangan. Lahan produktif pertanian terdiri dari hutan tanam industri, sawah, perikanan, perkebunan.

Formula untuk kerentanan ekonomi yaitu:

Kerentanan Ekonomi =

$(0,6 x$ skor lahan produktif $)+$ (0,4 x skor PDRB)

c. Kerentanan Fisik

Kerentanan fisik terdiri dari parameter jumlah rumah, jumlah fasilitas umum, dan jumah fasilitas kritis. Untuk fasilitas umum berupa sekolah dan fasilitas kesehatan. Untuk fasilitas kritis berupa bandara dan pelabuhan.Formula untuk kerentanan fisik yaitu :

Kerentanan Fisik =

$(0.4$ x skor rumah $)+(0.3 \times$ skor

fasilitas umum $)+(0.3 \times$ fasilitas

kritis)

d. Kerentanan Lingkungan

Kerentanan lingkungan terdiri dari beberapa perameter yaitu parameter luas hutan lindung, luas hutan alam, luas hutan bakau, luas semak belukar.

Formula untuk kerentanan lingkungan yaitu:

Kerentanan lingkungan $=$ (0.4 $x$ skor hutan lindung $)+$ $(0.3 \times$ skor hutan alam $)+(0.3$ $x$ skor hutan bakau $)+(0.1 x$ skor semak belukar)

3. Kapasitas Bencana Longsor

Parameter yang digunakan untuk peta kapasitas adalah indikator Hyugo Framework Action HFA yang terdiri dari: a)aturan dan kelembagaan penanggulangan bencana; b) peringatan dini dan kajian risikobencana; c) pendidikan kebencanaan; d) pengurangan faktor risiko dasar; dan e) pembangunan kesiapsiagaan pada seluruh lini. Informasi klasifikasi kapasitas bencana longsor mengacu pada tabel 4.

Tabel 4 Parameter konversi Indeks kapasitas bencana

\begin{tabular}{|c|c|c|c|c|c|}
\hline \multirow{2}{*}{ Parameter } & \multirow{2}{*}{$\begin{array}{l}\text { Bobot } \\
(\%)\end{array}$} & \multicolumn{3}{|c|}{ Kelas } & \multirow{2}{*}{ Skor } \\
\hline & & Rendah & Sedang & Tinggi & \\
\hline $\begin{array}{l}\text { Aturan } \\
\text { kelembagaan } \\
\text { penanggulan } \\
\text { gan bencana }\end{array}$ & \multirow{5}{*}{100} & \multirow{5}{*}{$<0.33$} & \multirow{5}{*}{$\begin{array}{c}0.33- \\
0.66\end{array}$} & \multirow{5}{*}{$>0.66$} & \multirow{5}{*}{$\begin{array}{c}\text { Kelas/ } \\
\text { Nilai } \\
\text { maksi } \\
\text { mal }\end{array}$} \\
\hline $\begin{array}{l}\text { Peringatan } \\
\text { dini dan } \\
\text { kajian } \\
\text { bencana }\end{array}$ & & & & & \\
\hline $\begin{array}{l}\text { Pendidikan } \\
\text { kebencanaan }\end{array}$ & & & & & \\
\hline $\begin{array}{l}\text { Pengurangan } \\
\text { faktor risiko } \\
\text { dasar }\end{array}$ & & & & & \\
\hline $\begin{array}{l}\text { Pembanguna } \\
\mathrm{n} \\
\text { kesiapsiagaa } \\
\mathrm{n} \quad \text { pada } \\
\text { seluruh lini }\end{array}$ & & & & & \\
\hline
\end{tabular}


Sumber : Perka BNPB No 2 Tahun 2012

\section{Risiko Bencana Longsor}

Analisis risiko bencana longsor menggunakan data hasil dari analisis ancaman bencana, kerentanan dan kapasitas. Masing masing parameter tersebut terlebih dahulu dianalisis dengan teknik skoring, setelah di skoring maka ke tiga parameter ini dianalisis lagi menggunakan formula Analisis risiko bencana menggunakan formula:

Risiko = Ancaman $\mathrm{x}$ Kerentanan $\mathrm{X}(1-\text { Kapasitas })^{0,333}$

Sumber : Perka BNPB No 2 Tahun 2012

\section{HASIL DAN PEMBAHASAN}

\section{Ancaman Bencana Longsor}

Pembuatan peta bahaya bencana longsor ini terdiri beberapa parameter yaitu kemiringan lereng, arah lereng, bentuk / panjang lereng, curah hujan, jenis tanah, kedalaman solum, tipe batuan, dan jarak dari sesar.

Kemiringan lereng kawasan Bukit Tui Kelurahan Koto Panjang terdiri dari kemiringan 0 hingga besar dari $70 \%$. Untuk parameter panjang lereng Bukit Tui Kelurahan Koto Panjang yaitu 1091 meter. Parameter tipe batuan di Kecamatan Koto Panjang terdiri dari Andesit Gunung Marapi (Qama), Andesit Gunung Singgalang dan Talang (Qast), dan Batu Gamping. Jarak Bukit Tui dari sesar aktif yaitu 52,2 meter.

Jenis tanah yang terdapat di Bukit Tui Kelurahan Koto Panjang yaitu Andosol dengan tekstur berliat berpasir dan Podsolik Merah Kuning dengan tekstur berliat berpasir. Kedalaman solum ke dua jenis tanah ini yaitu besar dari $90 \mathrm{~cm}$. Parameter curah hujan terdiri dari curah hujan minimal yaitu $2500 \mathrm{~mm}$ sedangkan curah hujan maskimal yaitu $3000 \mathrm{~mm}$. Keseluruhan parameter tersebut selanjutnya dioverlay untuk mendapatkan hasil berupa Peta Bahaya Longsor Bukit Tui Kelurahan Koto Panjang. Hasil analisis bahaya longsor dapat dilihat pada gambar 1.

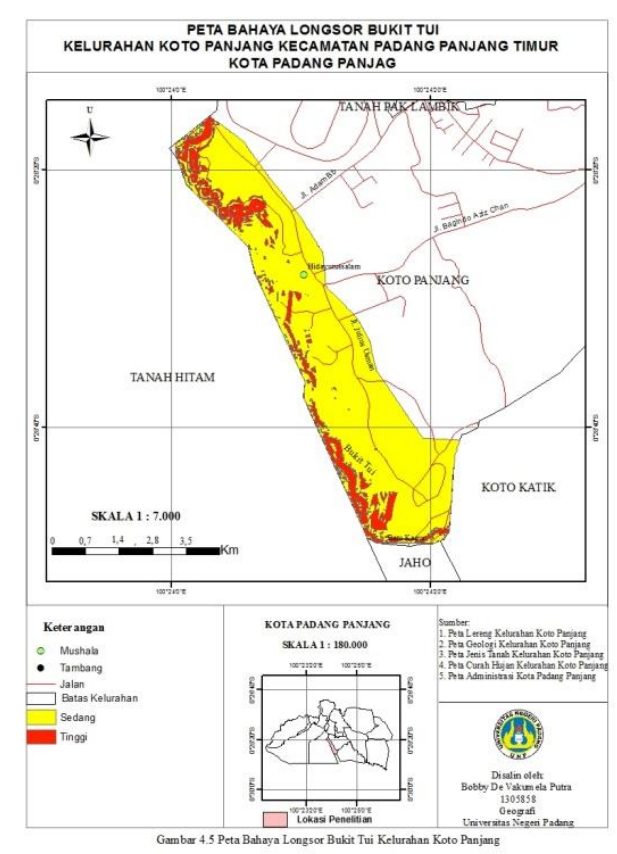

Gambar 1 Peta Bahaya Bencana Longsor

Dari Peta Bahaya Longsor Bukit

Tui Kelurahan Koto Panjang dapat diketahui bahwa sebagian besar wilayah Bukit Tui Kelurahan Koto Panjang berada di kawasan tingkat bahaya sedang. Luas daerah yang berada di kawasan bahaya sedang yaitu 17,64 ha, dengan persentase luas tingkat bahaya longsor sedang yaitu $86,55 \%$ dari luas keseluruhan kawasan Bukit Tui. Hasil dari Peta Bahaya Longsor ini juga menunjukan bahwa selain berada pada tingkat bahaya sedang, kawasan Bukit Tui Kelurahan Koto Panjang juga berada pada tingkat bahaya tinggi. Luas 
tingkat bahaya tinggi yaitu 2,74 $\mathrm{Ha}$ dengan persentase luas tingkat bahaya longsor tinggi yaitu 13,4\%.

\section{Kerentanan Bencana Longsor}

Tingkat kerentanan bencana didapat dari analisis empat parameter kerentanan yaitu kerentanan fisik, kerentanan sosial, kerentanan ekonomi, dan kerentanan lingkungan. Hasil analisis tersebut berupa Peta Kerentanan Kelurahan Koto Panjang. Dari peta tersebut kita akan mengetahui kerentanan Kelurahan Koto Panjang.

Dari peta kerentanan Bukit Tui Kelurahan Koto Panjang didapatkan hasil berupa kerentanan dalam tingkat sedang. Beradasarkan hasil analisis yang telah dilakukan kerentanan fisik berada di tingkat kerentanan sedang, kerentanan ekonomi berada di tingkat kerentanan rendah, sedang dan tinggi, kerentanan sosial berada di tingkat kerentanan sedang, dan kerentanan lingkungan berada di tingkat kerentanan rendah. Informasi hasil analisis kerentanan bencana longsor dapat dillihat pada tabel 6 .

Tabel 6 Hasil Analisis Kerentanan Bencana Longsor

\begin{tabular}{|l|l|l|l|l|}
\hline NO & PARAMETER & HASIL & KLASIFIKASI & SKOR \\
\hline 1. & Kerentanan & 0,66 & Sedang & 0,264 \\
& Fisik & & & \\
\hline 2. & Kerentanan & 0,565 & Sedang & 0,226 \\
& Sosial & & & \\
\hline 3. & Kerentanan & 0,33 & Rendah & 0,598 \\
& Ekonomi & 0,66 & $\begin{array}{l}\text { Sedang } \\
\text { Tinggi }\end{array}$ & 0,796 \\
& & & & 1 \\
\hline 4. & Kerentanan & 0,333 & Rendah & 0,0333 \\
\hline
\end{tabular}

Sumber: Hasil Pengolahan Data Sekunder

a. Kerentanan Sosial

Kerentanan sosial berasal dari beberapa parameter pembentuk yaitu jumlah penduduk, jumlah penduduk miskin, penduduk cacat, kelompok usia balita dan lansia. Dari beberapa parameter tersebut di lakukan analisis seperti perhitungan kepadatan penduduk, rasio jenis kelamin, rasio kemiskinan, rasio penduduk cacat, rasio kelompok umur.

Hasil dari analisis yang telah dilakukan didapatkan kepadatan penduduk sebesar 4779 jiwa $/ \mathrm{km}^{2}$. Kepadatan penduduk tersebut termasuk kedalam klasifikasi kepadatan penduduk tinggi karena lebih dari 1000 jiwa/m². Untuk rasio jenis kelamin didapatkan hasil sebesar 105 dengan klasifikasi tinggi. Rasio penduduk miskin didapatkan hasil sebesar 28,27 dengan klasifikasi sedang. Untuk rasio penduduk cacat dipatkan hasil sebesar 1,33 dengan klasifikasi rendah. Dan untuk rasio kelompok umur didapatkan hasil sebesar 25,02 dengan klasifikasi sedang.

Dari menjumlahkan keseluruhan parameter tersebut di dapatkan skor sebesar 0,565 untuk kerentanan sosial. Skor tersebut termasuk dalam klasifikasi kerentanan sosial sedang. Informasi hasil analisis dapat dilihat pada tabel 7 .

Tabel 7 Tabel Hasil Analisis Kerentanan Sosial

\begin{tabular}{|c|c|c|c|}
\hline No & Parameter & Hasil & Klasifikasi \\
\hline 1. & $\begin{array}{c}\text { Kepadatan } \\
\text { Penduduk }\end{array}$ & $\begin{array}{c}4779 \text { Jiwa } \\
/ \mathrm{Km}^{2}\end{array}$ & Tinggi \\
\hline 2. & Rasio Kelamin & 105 & Tinggi \\
\hline 4. & $\begin{array}{l}\text { Rasio Penduduk } \\
\text { Miskin }\end{array}$ & 28,27 & Sedang \\
\hline 5. & $\begin{array}{c}\text { Rasio Penduduk } \\
\text { Cacat }\end{array}$ & 1,33 & Rendah \\
\hline
\end{tabular}

Sumber: Hasil Pengolahan Data sekunder

b. Kerentanan Ekonomi 
Kerentanan ekonomi terdiri dari dua parameter pembentuk yaitu Lahan Produktif, dan PDRB. Analisis lahan produktif di Bukit Tui Kelurahan Koto Panjang didapatkan luas lahan produktif sebesar 6,669 ha. Jenis lahan produktif yang ada di kawasan Bukit Tui Kelurahan Koto Panjang yaitu sawah, perkebunan, tanaman campuran. Harga lahan produktif perkebunan sebesar Rp27,96 Juta. Harga lahan produktif sawah sebesar Rp 16,9 Juta. Dan harga lahan produktif tanaman campuran sebesar Rp 232,7 Juta.

Pada tahun 2016 PDRB untuk Bukit Tui Kelurahan Koto Panjang yaitu sebesar Rp 40,525 milyar. Hasil dari analisis parameter lahan produktif dengan analisis PDRB maka di dapatkan kerentanan ekonomi Kelurahan Koto Panjang ini terdiri dari kerentanan sedang dan tinggi. Hal ini karena besarnya harga lahan produktif yang berada di wilayah bahaya bencana longsor. Informasi hasil Analisis dapat dilihat pada tabel 8 .

Tabel 8 Tabel Hasil Analisis Kerentanan Ekonomi

\begin{tabular}{|l|l|l|l|}
\hline No & Parameter & Hasil & Klasifikasi \\
\hline 1. & $\begin{array}{l}\text { Harga } \\
\text { Lahan } \\
\text { Produktif } \\
\text { Perkebunan }\end{array}$ & Rp 27.964.000 & Rendah \\
\hline 2. & $\begin{array}{l}\text { Harga } \\
\text { Lahan } \\
\text { Produktif } \\
\text { Sawah }\end{array}$ & Rp 16.913.450 & Rendah \\
\hline 3. & $\begin{array}{l}\text { Harga } \\
\text { Lahan } \\
\text { Produktif } \\
\text { Tanah } \\
\text { Campuran }\end{array}$ & $\begin{array}{l}\text { Rp } \\
\text { 232.716.000 }\end{array}$ & Tinggi \\
\hline 4. & $\begin{array}{l}\text { Pdrb } \\
\text { Kawasan }\end{array}$ & $\begin{array}{l}\text { Rp } \\
40.525 .000 .000\end{array}$ & Tinggi \\
\hline
\end{tabular}

Sumber : Pengolahan Data Sekunder c. Kerentanan Fisik

Kawasan Bukit Tui Kelurahan Koto Panjang jumlah rumah yang berada di kawasan bahaya bencana longsor tingkat sedang sebanyak 50 rumah. Rumah yang berada pada bahaya tingkat tinggi sebanyak 6 rumah. Nilai ganti rugi untuk kerentanan fisik rumah sebesar Rp 590 juta. Kerentanan fisik parameter jumlah rumah di Kelurahan Koto Panjang ini termasuk klasifikasi kerentanan sedang.

Kawasan Bukit Tui Kelurahan Koto Panjang tidak memiliki fasilitas umum dan fasilitas kritis, maka untuk nilai fasilitas umum dan fasilitas kritis diberi nilai 0 . Dari hasil analisis kerentanan fisik didapat skor 0,56. Hasil analisis tersebut menunjukan bahwa kawasan Bukit Tui Kelurahan Koto Panjang berada dalam kerentanan fisik klasifikasi sedang. Informasi hasil analisis dapat dilihat pada tabel 9.

Tabel 9 Hasil Analisis Kerentanan Fisik

\begin{tabular}{|l|l|r|c|c|}
\hline No & Parameter & Jumlah & Hasil & $\begin{array}{c}\text { Klasifi } \\
\text { kasi }\end{array}$ \\
\hline 1. & $\begin{array}{l}\text { Rumah } \\
\text { Tingkat } \\
\text { Bahaya } \\
\text { Sedang }\end{array}$ & 50 & Rp 500.000.000 & Sedang \\
\hline 2. & $\begin{array}{l}\text { Rumah } \\
\text { Tingkat } \\
\text { Bahaya } \\
\text { Tinggi }\end{array}$ & 6 & Rp 90.000.000 & Rendah \\
\hline \multicolumn{3}{|l|}{$\begin{array}{l}\text { Sumber: } \\
\text { Sekunder }\end{array}$} & Pengolahan Data \\
\end{tabular}

d. Kerentanan Lingkungan

Dari peta kerentanan lingkungan didapatkan hasil berupa, kawasan Bukit Tui Kelurahan Koto Panjang hanya memiliki parameter hutan lindung dengan luas 14,69 Ha. Luas ini termasuk dalam klasifikisi 
tingkat rendah karena kecil dari 20 Ha. Untuk paramater lain seperti hutan alam, hutan bakau,semak belukar berdasarkan peta kerentanan lingkungan Bukit Tui Kelurahan Koto Panjang, di Bukit Tui Kelurahan Koto Panjang tidak memiliki ketiga parameter tersebut. Berdasarkan peta kerentanan tersebut dapat diketahui tingkat kerentanan lingkungan di Kelurahan Koto Panjang berada ditingkat kerentanan lingkungan rendah. Informasi hasil analisis dapat dilihat pada gambar 2 .

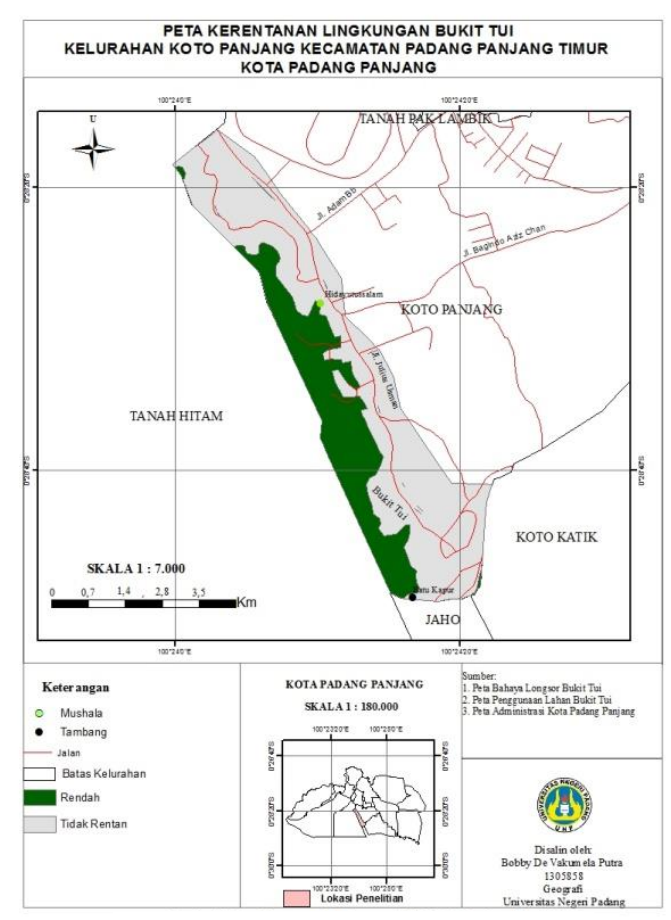

Gambar 2 Peta Kerentanan Lingkungan

\section{Kapasitas Bencana Longsor}

Analisis kapasitas bencana ini didapatkan dengan cara wawancara ke lembaga atau dinas pemerintahan yang ada di wilayah tersebut. Ada 88 pertanyaan berdasarkan lima parameter prioritas analisis kapasitas bencana. Prioritas pertama yaitu aturan kelembagaan penanggulangan bencana, prioritas kedua yaitu peringatan dini dan kajian bencana. Prioritas ketiga yaitu pendidikan kebencanaan. Prioritas ke empat yaitu pengurangan faktor risiko dasar. Dan prioritas kelima yaitu pembangunan kesiapsiagaan pada seluruh lini. Masing - masing prioritas tersebut memiliki beberapa parameter.

Dari hasil wawancara tersebut untuk Kelurahan Koto Panjang didapatkan hasil berupa indeks daerah Kelurahan Koto Panjang sebesar 31,25. Jika dikonversi menjadi skor kapasitas didapatkan skor kapasitas Kelurahan Koto Panjang sebesar 0,207055. Dari skor tersebut didapatkan tingkat kapasitas Kelurahan Koto Panjang pada tingkat kapasitas rendah. Untuk aturan kelembagaan penanggulangan bencana Kelurahan Koto Panjang didapatkan skor 62,5. Parameter peringatan dini dan kajian bencana didapatkan skor 43,75. Parameter pendidikan kebencanaan mempunyai skor 25 . Untuk pengurangan faktor risiko dasar 8,32. Parameter pembangunan kesiapsiagaan pada seluruh lini memiliki skor 31,25. Informasi hasil analisis dapat dilihat pada tabel 10 .

Tabel 10 Hasil Analisis Kapasaitas Kelurahan Koto Panjang

\begin{tabular}{|l|l|r|}
\hline No & \multicolumn{1}{|c|}{ Parameter } & \multicolumn{1}{c|}{ Skor } \\
\hline 1. & $\begin{array}{l}\text { Aturan } \\
\text { Kelembagaan } \\
\text { Penanggulangan } \\
\text { Bencana }\end{array}$ & 62,5 \\
\hline 2. & $\begin{array}{l}\text { Peringatan Dini dan } \\
\text { Kajian Bencana }\end{array}$ & 4,75 \\
\hline 3. & $\begin{array}{l}\text { Pendidikan } \\
\text { Kebencanaan }\end{array}$ & 25 \\
\hline 4. & Risiko Dasar & 31,25 \\
\hline 5. & $\begin{array}{l}\text { Pembangunan } \\
\text { Kesiapsiagaan pada } \\
\text { Seluruh Lini }\end{array}$ \\
\hline
\end{tabular}


Sumber : Pengolahan Data Primer

\section{Risiko Bencana Longsor}

Analisis risiko bencana longsor membutuhkan beberapa parameter yaitu parameter bahaya longsor, kerentanan, kapasitas bencana. Ketiga parameter tersebut di analisis dengan formula sebagai berikut;

Bahaya x Kerentanan x (1- Kapasitas)^^${ }^{\wedge 0,333}$.

Hasil dari analisis tersebut didapatkan bahwa Kelurahan Koto Panjang berada pada tingkat risiko bencana longsor sedang dan risiko bencana longsor rendah. Luas risiko bencana tingkat rendah yaitu seluas 17,93 ha dengan persentase luas bahaya rendah sebesar $87,93 \%$. Pada kawasan risiko sedang ini terdapat penggunaan lahan berupa permukiman, sawah, tanaman campuran, peribadatan. Luas risiko bencana tingkat sedang yaitu 2,46 Ha dengan persentase luas 12,06\%. Pada kawasan risiko becana longsor sedang sebagian besar penggunaan lahannya berupa hutan. Kawasan risiko sedang ini memiliki kemiringan lereng lebih dari $50 \%$. Peta hasil analisis risiko dapat dilihat pada gambar 3 .

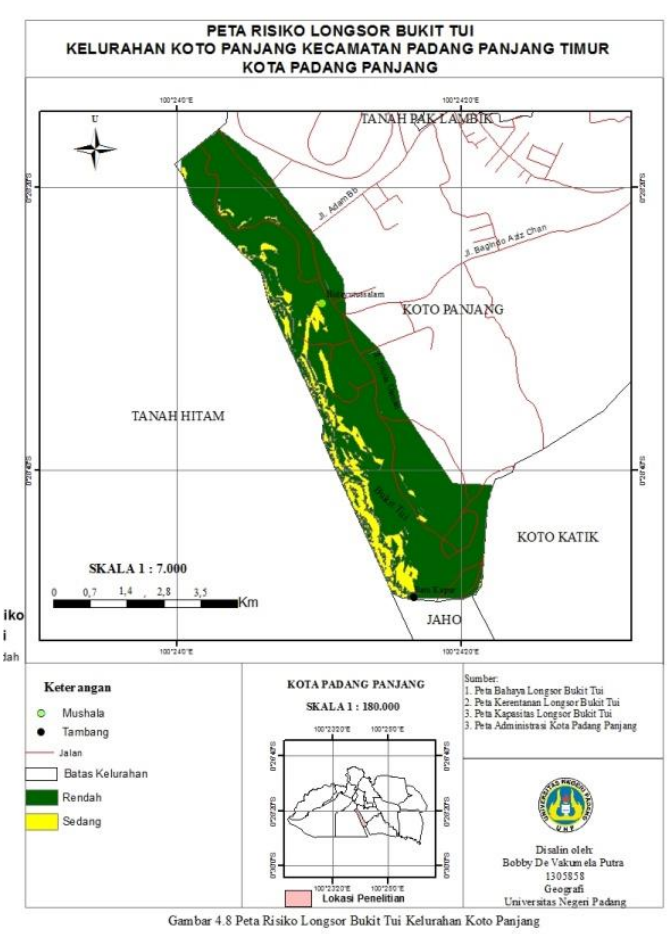

Gambar 3. Peta Risiko Bencana Longsor

\section{PENUTUP \\ Kesimpulan}

Adapun kesimpulan dalam penelitian ini yaitu:

1. Tingkat bahaya bencana longsor di Kelurahan Koto Panjang Kecamatan Padang Panjang Timur sebagian besar berada dalam tingkat bahaya sedang dengan luas 17,64 ha dengan persentase luas $86,55 \%$. Wilayah yang berada ditingkat bahaya longsor tinggi memiliki luas sebesar 2,76 ha dengan persentase luas $13,4 \%$.

2. Kerentanan bencana longsor di Bukit Tui Kelurahan Koto Panjang Kecamatan Padang Panjang Timur berada ditingkat keretanan bencana sedang.

3. Kapasitas bencana longsor di Bukit Tui Kelurahan Koto Panjang Kecamatan Padang Panjang Timur berada dalam tingkat kapasitas rendah. 
4. Tingkat risiko bencana longsor di Bukit Tui Kelurahan Koto Panjang Kecamatan Padang Panjang Timur yaitu sebagian besar dalam tingkat risiko rendah dan tingkat risiko sedang. Wilayah yang berada dalam tingkat risiko rendah memiliki luas sebesar 17,93 ha persentase luas risiko sedang yaitu $87,93 \%$ dan wilayah yang berada di tingkat risiko sedang yaitu sebesar 2,46 ha dengan persentase luas $12,06 \%$.

\section{Saran}

Adapun saran dalam penelitian ini yaitu:

1. Perlunya aturan dan pengawasan dalam pemanfaatan lahan yang terrletak dalam daerah bencana longsor. Hal ini berguna untuk mengurangi kerugian jika terjadi bencana.

2. Perlunya aturan bagi yang tegas bagi masyarakat agar tidak mendirikan rumah di kawasan bahaya bencana longsor. Hal ini berguna dalam mengurangi tingkat kerentanan.

3. Perlunya peningkatan kapasitas bencana longsor berupa pemberian informasi dan pendidikan mengenai hal yang di lakukan jika terjadi bencana. Peningkatan kapasitas ini nantinya akan berguna dalam mengurangi jumlah korban jiwa maupun materi jika sewaktu-waktu terjadi bencana.

4. Pada kawasan dengan tingkat resiko tinggi diharapkan agar tidak melakukan kegiatan yang akan menimbulkan kerugian jika suatu saat terjadi bencana

\section{DAFTAR PUSTAKA}

Antara News.(2010, 28 Februari). Denting Martil Itu Masih Terdengar.https://sumbar.antara news.com/berita/134350/denting -martil-itu-masih-terdengar-dibukit-tui.html. (diakses 15 Februari 2018)

Badan Nasional Penanggulangan Bencana. (2012). Peraturan Kepala BNPB No. 02 Tahun 2012 tentang Pedoman Umum Pengkajian Risiko Bencana. Jakarta.

Badan Nasional Penanggulangan Bencana, (2012). Peraturan Kepala BNPB No 03 Tahun 2012 tentang Panduan Penilaian Kapasitas Daerah Dalam Penanggulangan Bencana

Badan Pusat Statistik Kota Padang Panjang. (2017). Padang Panjang Dalam Angka 2017. Padang Panjang : Badan Pusat Statistik.

Nandi. 2007. Longsor. Jurusan Pendidikan Geografi. Bandung. FPIPS-UPI

PB,Triton.2009.Menganal

Sains

Sejarah Bumi dan Bencana Alam.Yogyakarta: Tugu

Republik Indonesia. 2007. Undang Undang No 24 Tahun 2007 tentang Penanggulangan Bencana. Lembaran Negara RI Tahun 2007. No 4723. Sekertariat Negara. Jakarta. 